\title{
BURDEN OF MALARIA AT COMMUNITY LEVEL IN CHILDREN LESS THAN 5 YEARS OF AGE IN TOGO
}

\author{
M. JAMES ELIADES,* ADAM WOLKON, KODJO MORGAH, SARA B. CRAWFORD, AMEYO DORKENOO, \\ YAO SODAHLON, WILLIAM A. HAWLEY, ALLEN W. HIGHTOWER, FEIKO O. TER KUILE, AND \\ DIANNE J. TERLOUW \\ Malaria Branch, Division of Parasitic Diseases, Centers for Disease Control and Prevention, Atlanta, Georgia; National Malaria \\ Program, Togo Ministry of Health, Lome, Togo; Liverpool School of Tropical Medicine, Liverpool, United Kingdom
}

\begin{abstract}
A community-based baseline cross-sectional survey was conducted in three districts in Togo in September 2004 as part of a multidisciplinary evaluation of the impact of the Togo National Integrated Child Health Campaign. During this campaign, long-lasting-insecticide-treated bed nets (LLITNs) were distributed to households with children between 9 months and 5 years of age throughout the country in December 2004. The pre-intervention survey provided baseline malaria and anemia prevalence in children $<5$ years of age during peak malaria transmission. Of 2,532 enrolled children from 1,740 households, $62.2 \%(1,352 / 2,172)$ were parasitemic and $84.4 \%(2,129 / 2,524)$ were anemic (hemoglobin $<11 \mathrm{~g} / \mathrm{dL})$. Moderate-to-severe anemia $(<8.0 \mathrm{~g} / \mathrm{dL})$ was found in $21.7 \%(543 / 2,524)$, with a peak prevalence in children 6-17 months of age and was strongly correlated with parasitemia (OR $=2.3,95 \%$ CI: $1.8-2.5)$. Net ownership (mainly untreated) was 225/2,532 (8.9\%). Subsequent nation-wide introduction of LLITNs and the introduction of artemisinin-based combination therapy have the potential to markedly reduce this burden of malaria.
\end{abstract}

\section{INTRODUCTION}

Malaria is holoendemic in much of sub-Sahelian West Africa. In Togo, the national Health Facility-Level Malaria Surveillance System ${ }^{1}$ confirms that malaria is endemic throughout the country. Evidence supporting this conclusion comes from documented malaria prevalence from neighboring countries and interpolated malaria transmission risk from the Mapping Malaria Risk in Africa/Atlas du Risque de la Malaria en Afrique (MARA/ARMA) ${ }^{2}$ mapping effort. Few studies, however, have described the age-related burden of malaria or anemia within Togo, and there is a dearth of information on the burden at a community level.

In December 2004, > 900,000 long-lasting insecticidetreated bed nets (LLITNs) were distributed throughout the country to households with children between the ages of 9 months and 5 years as part of the Togo National Integrated Child Health campaign. ${ }^{3}$ This campaign aimed to lower morbidity and mortality in young children in Togo through integrated bed net distribution, measles vaccination, polio vaccination, and presumptive treatment of helminth infections. As part of a multidisciplinary evaluation of the impact of this campaign, the pre- and post-intervention burden of malaria and anemia at community level in children age $<5$ years was compared. Repeat cross-sectional surveys were conducted in rural areas representative of the range in climatic patterns in Togo during the high transmission season in 2004 and 2005. Here, we present the results of the baseline survey conducted in September 2004.

\section{MATERIALS AND METHODS}

Study site. The study was conducted in rural communities from three districts: Yoto in the southern Maritime region, Ogou in the central Plateaux region, and Tone, the most northern district in the Savanes region (Figure 1). Because of the country's length, its climate varies from humid tropical in the south to semiarid in the north. Malaria transmission in

* Address correspondence to M. James Eliades, Centers for Disease Control and Prevention, 4770 Buford Highway, MS F-22, Atlanta, GA 30341. E-mail: bvz9@cdc.gov
Togo reflects its rainfall patterns, with a bimodal pattern (with long rains from March to June and short rains from September to October) in the south, a single long stable rainy season (from March to October) in the Plateaux Region (Ogou), and a shorter, single rainy season (from May to September, with peak rainfall in August) in the north.

Study population. Togo has a population of 5.7 million, with an estimated 980,000 children $<5$ years of age $(17.2 \%)^{4,5}$ and an estimated 75,000 live births per year. ${ }^{6}$ The country's population is ethnically heterogeneous, consisting of 37 different groups. Most people in rural areas are subsistence farmers. A few cash crops such as cotton are also grown. Around $53 \%$ of the adult population in the country is literate, a figure that varies widely between regions, with the lowest literacy rate of $16 \%$ in the northern Savanes region. ${ }^{6}$

Study design and sample size. A community-based crosssectional survey was conducted in children $<5$ years of age from rural areas. The study used a stratified two-step cluster sample design with clusters at the district and enumeration area (EA) levels. District level sample size was based on the estimated effect of ITNs on malaria morbidity. The study was designed to have $80 \%$ power to detect a $33 \%$ reduction between pre- and post-intervention prevalence of moderate-tosevere anemia (hemoglobin level $[\mathrm{Hb}]<8.0 \mathrm{~g} / \mathrm{dL}$ ), with $95 \%$ confidence. Sample size calculations were made assuming $70 \%$ of households to have children $<5$ years of age, $45 \%$ of households with children to have more than one child, a nonresponse rate of $10 \%$, a design effect of 1.5 , and a baseline overall prevalence of moderate-to-severe anemia of $20 \%$. The 1998 Togo census provided the sampling frame of defined EAs with 1998 population sizes between 606 and 1,420. Sample size calculations were done using the StatCalc module (EpiInfo 2000, Centers for Disease Control and Prevention, Atlanta, GA).

Based on 20 years of monthly retrospective rainfall data, there are three distinct regional rainfall patterns within the country. One district was selected within each of these regions to represent the variation in transmission patterns within Togo. In total, 90 rural EAs were selected (30 per district) by random sampling with a probability proportional to size (PPS). Each EA was mapped in its entirety using a global 


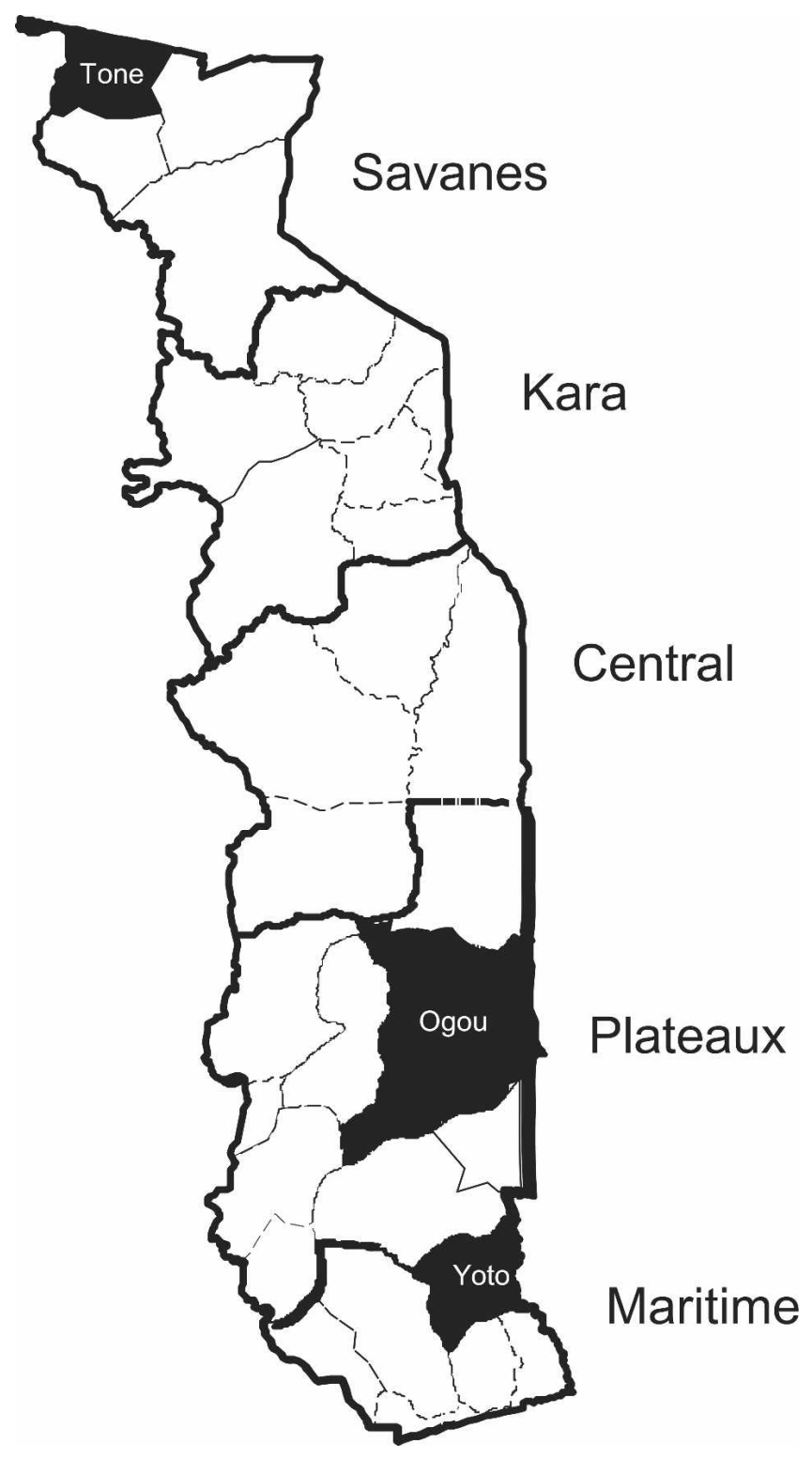

Figure 1. Map Togo: regions and selected districts.

positioning system unit (GPS) attached to a personal digital assistant (PDA). Each household was assigned a random number at the time of mapping. Within each EA, a random sample of 25 households was selected regardless of the presence of children $<5$ years of age, with the aim to enroll an average of $27-30$ children $<5$ years per cluster. The survey was conducted in September 2004 at the beginning of the second or short rainy season in Yoto and the end of the main rainy season in Ogou and Tone.

Study procedures. Each of the three districts was surveyed in 6 working days with the help of six GPS (Global Positioning System) and six survey teams. The six GPS teams, consisting of two members each, mapped six EAs per day. Using census-based maps that indicated EA borders and personal digital assistants (PDA; Dell Axim X5s; Dell, Austin, TX) equipped with GPS units (Pharos, Torrance, CA), one GPS team would map all households within one selected EA each day. After mapping the EA, a random selection of 25 households and 15 alternates were selected by the team while in the field, using a survey specific program developed by the Centers for Disease Control and Prevention. That same day, GPS teams revisited the selected households and invited households who confirmed the presence of children $<5$ years of age to participate in the survey. A household was defined as one mother or primary care taker and their children. If more than one wife was present in a household, one was randomly selected by drawing straws. If the team was unable to locate the family at a household, an alternate was chosen from the PDA-generated list of 15 alternate houses. Alternates were not chosen for refusal to participate or if the household did not have a child $<5$ years of age.

Data and specimen collection took place 2-3 days later at a central, well-known location within the involved EA. District survey teams consisted of five individuals each: a supervisor; two surveyors to gather background data on demographics and medical history; a physician; and a laboratory assistant. Specimens taken were a capillary blood sample for assessment of Hb level (Hemocue, Angelholm, Sweden), presence of malaria parasites by rapid diagnostic test (RDT, Paracheck Pf; Orchid Biomedical Systems, Verna, Goa, India), and a malaria thin and thick blood smear. A brief medical exam was performed by a medically qualified staff member and appropriate treatment was provided to children with anemia (iron syrup $2-3 \mathrm{mg} / \mathrm{kg} /$ day of elementary iron for a minimum of 4 weeks) and parasitemia as determined by RDT (ArtesunateAmodiaquine, Arsucam, Sanofi-Synthelabo, Paris, France). Children with acute illness that needed further attention were referred to the nearest health facility. Invited households who did not attend were visited at home to remind them of the survey or confirm the reason for their absence. Included in the background and demographic household data were an economic questionnaire based on criteria and associated scoring system developed by the World Bank to classify each household's economic status into wealth quintiles. ${ }^{7}$

Laboratory analysis. Thick and thin blood smears were stained with Giemsa and examined for parasites. Parasite densities were counted against 500 leukocytes and expressed per cubic millimeter of blood using an assumed leukocyte count of $8,000 / \mathrm{mm}^{3}$. Malaria thick and thin smears were read at the malaria reference laboratory of the Ministry of Health in Lome, with a sub-sample examined for quality control at a Centers for Disease Control malaria laboratory. The calibration of the used Hemocue machines (precision, $\pm 0.2 \mathrm{~g} / \mathrm{dL}$ ) was checked daily in the field using control cuvettes.

Data management and statistical methods. All answers were entered directly into a database on the PDAs while in the field (questionnaire application software: Visual CE 8.0; Syware, Cambridge, MA), which was downloaded daily into a central database (Microsoft Access). Data entry errors were limited by the use of data entry screens with drop-down menus and internal consistency checks. Data were further cleaned using range and internal consistency checks. Analyses were performed using SAS (version 9.1; SAS Institute, Cary, NC). Weighted frequencies, percentages, and $\chi^{2}$ tests of association were calculated using proc surveyfreq in SAS. We explored associations between various binary variables of interest while controlling for other covariates using logistic regression. Those relationships explored controlling for other covariates were assessed using logistic regression with proc surveylogistic. Analyses were weighted for the number of invited households, because this varied over the first 3 days of 
the survey, and took the survey design into account by adjusting for clustering at the enumeration area level.

Definitions. Fever was defined as a documented axillary temperature $\geq 37.5^{\circ} \mathrm{C}$. Anemia, moderate-to-severe anemia, and severe anemia were defined as $\mathrm{Hb}$ concentrations $<11.0$, $<8.0$, and $<5.0 \mathrm{~g} / \mathrm{dL}$, respectively. Malaria parasitemia was defined as any asexual parasitemia detected on a thick or thin blood smear. Clinical malaria was defined as a documented axillary temperature $\geq 37.5^{\circ} \mathrm{C}$ with malaria parasitemia. High-density parasitemia was defined as an asexual parasite density of $>5,000 / \mathrm{mm}^{3}$.

Ethical clearance and informed consent. This survey was reviewed and approved by institutional review boards of the Togo Ministry of Health, the Liverpool School of Tropical Medicine, and the Centers for Disease Control and Prevention. Written informed consent was obtained from the caretakers for each individual participant by a signature or ink thumbprint, after explanation of the study procedures in the local language.

\section{RESULTS}

In total, 2,304 households were randomly selected for participation, and 1,822 (79.1\%) of them reported having at least one child $<5$ years of age $(70.1 \%, 80.4 \%$, and $87.1 \%$ in Yoto, Ogou, and Tone, respectively). Of eligible households, $95.5 \%$ were enrolled $(94.3 \%, 93.5 \%$, and $98.3 \%$ for Yoto, Ogou, and Tone, respectively). The median number of children enrolled per EA was 29 (range $=11-51$ ). The main reason for nonenrollment was absence at the day of the survey related to travel or work in the field $(5.3 \%, 6.4 \%$, and $1.7 \%$ in Yoto, Ogou, and Tone, respectively). Only two (0.1\%) eligible households refused to participate. Seventy enrolled children born in 1999 who had participated were excluded from the analysis because their dates of birth revealed they were 60 months at the date of the survey. The age of the child was confirmed in $60 \%(1,480$, weighted number $)$ of cases with a vaccination card, and the average age was 28.5 months. Overall, 2,532 children from 1,740 households contributed to the analysis.

Household characteristics. The main characteristics of the 1,740 enrolled households are presented by district in Table 1. Of these, $42.7 \%$ had more than one child $<5$ years of age, a figure that was similar in all three selected districts $(43.9 \%$, $40.1 \%$, and $44.1 \%$ in Yoto, Ogou, and Tone, respectively). There were no significant differences in socio-economic status among the districts, with a similar percentage of households below the median in all three districts. Most people in the lowest economic quintile lived in households with mud floors and thatched roofs, whereas those in the other four quintiles lived in households with cement floors and either thatched or metal roofs. Few households in the poorest four economic quintiles reported having electricity or the use of any type of toilet, whereas only $15.9 \%$ in the wealthiest quintile reported electricity and approximately one half reported the use of some type of latrine. People in the lowest quintiles tended to get their water from lakes or rivers, whereas those in the wealthier quintiles tended to have access to some type of well. Caretaker education level was considerably lower in Tone compared with the other two districts $(P<0.0001)$.

History of illness, health care-seeking behavior, prevention, and treatment. Table 2 shows recent history of illness,
TABLE 1

Baseline household characteristics of 1,740 households enrolled in baseline survey September 2004

\begin{tabular}{|c|c|c|c|}
\hline & $\begin{array}{c}\text { Yoto } \\
(n=489)^{*}\end{array}$ & $\begin{array}{c}\text { Ogou } \\
(n=566)\end{array}$ & $\begin{array}{c}\text { Tone } \\
(n=642)\end{array}$ \\
\hline \multicolumn{4}{|c|}{ No. enrolled children $<5$ years per $\mathrm{HH}, n(\%)$} \\
\hline 1 & $275(56.1 \%)$ & $339(59.9 \%)$ & $359(55.9 \%)$ \\
\hline 2 & $190(38.8 \%)$ & $213(37.6 \%)$ & $262(40.8 \%)$ \\
\hline 3 & $22(4.5 \%)$ & $14(2.5 \%)$ & $21(3.3 \%)$ \\
\hline$>3$ & $3(0.6 \%)$ & $0(0 \%)$ & $0(0 \%)$ \\
\hline \multicolumn{4}{|l|}{ Caretaker, $n(\%)$} \\
\hline Mother & $421(86.1 \%)$ & $490(86.6 \%)$ & $607(94.5 \%)$ \\
\hline Father & $31(6.4 \%)$ & $55(9.7 \%)$ & $19(3.0 \%)$ \\
\hline Grandparent & $25(5.1 \%)$ & $11(1.9 \%)$ & $5(0.8 \%)$ \\
\hline Other & $12(2.4 \%)$ & $10(1.8 \%)$ & $11(1.7 \%)$ \\
\hline \multicolumn{3}{|l|}{ Economic status, } & $323(50.3)$ \\
\hline \multicolumn{4}{|l|}{$\begin{array}{l}\text { Educational status } \\
\quad \text { caretaker, } n(\%)\end{array}$} \\
\hline No education & $308(62.9 \%)$ & $377(66.6 \%)$ & $559(87.1 \%)$ \\
\hline $\begin{array}{l}\text { Primary education } \\
\text { only }\end{array}$ & $136(27.7 \%)$ & $149(26.3 \%)$ & $67(10.4 \%)$ \\
\hline Higher education & $46(9.4 \%)$ & $40(7.1 \%)$ & $16(2.5 \%)$ \\
\hline $\begin{array}{l}\text { Ownership any bed net, } \\
n(\%)\end{array}$ & $56(11.4 \%)$ & $72(12.7 \%)$ & $32(5.0 \%)$ \\
\hline Ownership ITN, $n(\%)$ & $3(0.6 \%)$ & $2(0.4 \%)$ & $2(0.3 \%)$ \\
\hline
\end{tabular}

health care-seeking behavior, and treatment reported by the caretaker. Whereas most children were afebrile and asymptomatic at the time of the survey, $70.9 \%$ were reported to have had a fever within the previous 2 weeks, $23.1 \%$ of children were reported to have had fever and sought treatment (13.7\%, 25.5\%, and $28.2 \%$ in Yoto, Ogou, and Tone, respectively), and $11.1 \%$ were reported to have had convulsions. These proportions were similar within districts between younger and older children, but higher in the two northern districts. In the previous 2 weeks, $41.8 \%$ of children had reportedly taken anti-malarials; $46.7 \%$ of these treatments were obtained through contact with the public health care system. Chloroquine and quinine, the currently recommended firstline treatments for uncomplicated and severe malaria, respectively, were used most frequently; use of other anti-malarials was rare. Iron supplementation was reportedly used by $4.2 \%$ of children in the previous 2 weeks $(3.5 \%, 3.9 \%$, and $5.0 \%$ in Yoto, Ogou, and Tone, respectively). Caretakers reported that $22.5 \%$ of children had severe malaria (defined as illness with fever, vomiting, and/or convulsions) in the previous 2 months, and this proportion was similar in all three districts. All-cause hospital admission rates were different in the three districts $(P=0.001)$ with somewhat higher rates in Yoto $(3.5 \%)$ and Tone $(2.6 \%)$ than Ogou $(0.6 \%)$. Fifteen children were said to have received a blood transfusion in the previous 2 months.

ITN use. Ownership of a bednet was reported in $5-10 \%$ of the households. Less than $10 \%$ of the nets owned were treated with insecticide. The majority of households with nets reported owning a single net $(76.1 \%, 124 / 163)$. Net ownership was positively associated with socio-economic status $(P<$ 0.0001 ), with a coverage in the poorest quintiles that was $68 \%$ lower than the coverage in the richest quintile (equity ratio $=$ $0.32)$.

Prevalence of anemia. The majority of children were ane- 
TABLE 2

Characteristics, reported history, health care-seeking behavior, malaria, and anemia treatment in 2532 children*

\begin{tabular}{|c|c|c|c|c|}
\hline & $\begin{array}{c}\text { Yoto } \\
(n=724) \dagger\end{array}$ & $\begin{array}{c}\text { Ogou } \\
(n=804)\end{array}$ & $\begin{array}{c}\text { Tone } \\
(n=939)\end{array}$ & Crude $P \ddagger$ \\
\hline \multicolumn{5}{|l|}{ Characteristics } \\
\hline Age in months, mean $(95 \% \mathrm{CI})$ & $28.8(27.5-30.1)$ & $28.3(27.3-29.3)$ & $28.5(27.5-29.5)$ & 0.84 \\
\hline No. of males $(\%)$ & $381(52.6)$ & $400(49.8)$ & $522(55.6)$ & 0.03 \\
\hline \multicolumn{5}{|l|}{ History previous 2 weeks } \\
\hline Febrile episode + healthcare sought, $n(\%)$ & $98(13.7)$ & $204(25.5)$ & $262(28.2)$ & $<0.01$ \\
\hline \multicolumn{5}{|l|}{ Type health care facility visited for these febrile episodes } \\
\hline Out-patient health centre, $n$ (column \%) & $64(64.7)$ & $116(56.9)$ & $229(87.4)$ & \\
\hline Out-patient policlinic, $n$ (column \%) & $29(29.9)$ & $25(12.3)$ & $13(5.0)$ & \\
\hline In-patient hospital, $n$ (column \%) & $1(0.8)$ & $4(2.0)$ & $15(5.7)$ & \\
\hline Convulsions, $n(\%)$ & $78(10.7)$ & $152(18.9) \ddagger$ & $44(4.7)$ & $<0.01$ \\
\hline Received malaria medication in past 2 weeks, $n(\%)$ & $270(37.3)$ & $332(41.3)$ & $430(45.8)$ & 0.31 \\
\hline Chloroquine, $n$ (Column \%) & $237(87.7)$ & $310(93.4)$ & $383(89.1)$ & \\
\hline Sulfadoxine-pyrimethamine, $n$ (Column \%) & $16(5.9)$ & $8(2.4)$ & $9(2.1)$ & \\
\hline Amodiaquine, $n$ (Column \%) & $11(4.1)$ & $1(0.3)$ & $8(1.9)$ & \\
\hline ACT, $n$ (Column \%) & $0(0)$ & $0(0)$ & $1(0.2)$ & \\
\hline Quinine, $n($ Column \%) & $36(13.5)$ & $29(8.7)$ & $60(14.0)$ & \\
\hline Received blood transfusion, $n(\%)$ & $7(0.9)$ & $3(0.4)$ & $5(0.5)$ & 0.44 \\
\hline Received iron, $n(\%)$ & $26(3.5)$ & $31(3.9)$ & 47 (5.0) & 0.68 \\
\hline
\end{tabular}

mic $(84.4 \%, 2,129 / 2,524)$. The overall prevalence of moderate anemia $(\mathrm{Hb}<8.0 \mathrm{~g} / \mathrm{dL})$ was $21.7 \%(543 / 2,524 ; 16.3 \%, 23.5 \%$, and $23.1 \%$ in Yoto, Ogou, and Tone, respectively), whereas that of severe anemia $(\mathrm{Hb}<5.0 \mathrm{~g} / \mathrm{dL})$ was $0.8 \%(19 / 2,524)$. Figure 2 shows anemia level by age in each of the three districts. Whereas $\mathrm{Hb}$ levels were similar among all three districts, moderate-to-severe anemia prevalence varied considerably over age, with peak prevalence between the age of 6 and 17 months. There was no significant difference in $\mathrm{Hb}$ levels when comparing economic quintiles $(P=0.07)$. An $\mathrm{Hb}$ level $<8.0 \mathrm{~g} / \mathrm{dL}$ was more likely in parasitemic children compared with parasite-negative children $(\mathrm{OR}=2.3,95 \% \mathrm{CI}=$ 1.8-3.5, adjusted for age in months). This was also true with children with a positive RDT compared with those with a negative $\mathrm{RDT}(\mathrm{OR}=3.7,95 \% \mathrm{CI}=2.5-5.3$, adjusted for age in months). Table 3 shows associations of anemia and mod-

\section{$\square$ Yoto $\square$ Ogou $\square$ Tone}

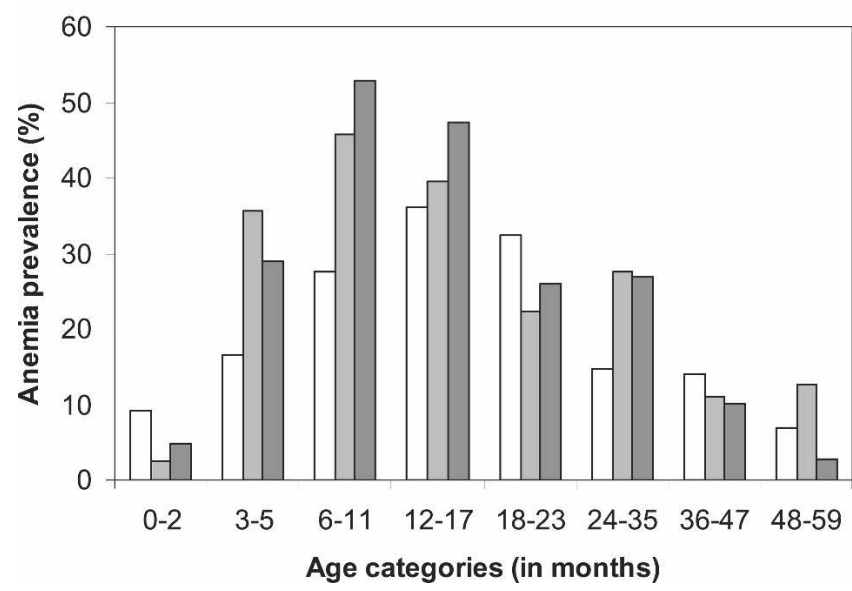

FIGURE 2. Mild and moderate-to-severe anemia prevalence by age. $(\mathrm{Hb}<8 \mathrm{~g} / \mathrm{dl})$. erate-to-severe anemia with age and household and clinical characteristics.

Prevalence of parasitemia. Of the 2,237 children for which blood smear results were available, $62.2 \%(1,352 / 2,172)$ were parasitemic. Distribution of parasitemia and clinical malaria by district and age is presented in Figures 3 and 4. Overall parasitemia prevalence increased rapidly in infancy from $18.2 \%$ ( $0-2$ months) to $43.0 \%$ (3-5 months) overall. Prevalence increased up to the age of 2-3 years and remained high up to the age of 5 years, ranging from $69.4 \%$ to $73.0 \%$. Distribution of clinical malaria by district and age is presented in Figure 4 and shows a relatively stable prevalence for children of all ages after the first 2-5 months of life. Parasite burden and prevalence of clinical malaria was not significantly different in the three districts. Of the children with parasitemia, $23.3 \%$ had a documented fever at the time of the survey. Splenomegaly (a Hackett score $>0$ ) was present in $>19 \%$ of children and varied considerably between districts $(28.5 \%$, $38.0 \%$, and $19.9 \%$ in Yoto, Ogou, and Tone, respectively, $P<$ $0.001)$ as well as between observers of the six teams within the districts $(P=0.0001, P<0.0001$, and $P<0.0001$ for Yoto, Ogou, and Tone, respectively).

There was no significant difference in the percentage of children with parasitemia between economic quintiles, controlling for age and bednet use, in Yoto $(P=0.33)$ and Ogou $(P=0.19)$. In Tone, there was a significant difference in parasitemia between children in the wealthiest and poorest quintiles $(P=0.03)$, but no difference among children in the poorest four quintiles (percentage of parasitemic children by economic quintile, poorest to wealthiest, in Tone: $64.5 \%$, $67.6 \%, 67.3 \%, 64.6 \%$, and $48.4 \%$ ). Children who were reported to have slept under a bednet (predominantly untreated with insecticide) were no less likely to be parasitemic than those who did not when controlling for age $(P=0.08)$.

As with moderate-to-severe anemia, the presence of a highdensity infection $\left(>5,000 / \mathrm{mm}^{3}\right)$ was most prevalent in children 6-17 months. Increasing parasite density was associated 
TABLE 3

Association of anemia and moderate-to-severe anemia with household and clinical characteristics in 2,524 children*

\begin{tabular}{|c|c|c|c|c|}
\hline Characteristics & $\begin{array}{c}\mathrm{Hb}<11.0 \mathrm{~g} / \mathrm{dL} \\
{[n(\%)]}\end{array}$ & $P \dagger$ & $\begin{array}{c}\mathrm{Hb}<8.0 \mathrm{~g} / \mathrm{dL} \\
{[n(\%)]}\end{array}$ & $P$ \\
\hline \multicolumn{5}{|l|}{ Age categories (months) } \\
\hline $0-2$ & $74(54.6)$ & & $8(6.0)$ & \\
\hline $3-5$ & $133(88.2)$ & & $43(28.5)$ & \\
\hline $6-11$ & $235(95.7)$ & & $105(42.7)$ & \\
\hline $12-17$ & $258(94.2)$ & & $115(41.8)$ & \\
\hline $18-23$ & $191(93.0)$ & & $56(27.1)$ & \\
\hline $24-35$ & $444(87.8)$ & & $119(23.5)$ & \\
\hline $36-47$ & $400(80.8)$ & & $57(11.5)$ & \\
\hline $48-59$ & $340(76.1)$ & $<.0001$ & $31(6.9)$ & $<.0001$ \\
\hline \multicolumn{5}{|l|}{ Region } \\
\hline Tone & $783(84.0)$ & & $215(23.1)$ & \\
\hline Ogou & $685(85.3)$ & & $189(23.5)$ & \\
\hline Yoto & $608(83.9)$ & 0.8296 & $129(17.8)$ & 0.0325 \\
\hline \multicolumn{5}{|l|}{ Clinical malaria } \\
\hline Yes & $195(92.2)$ & & $74(35.1)$ & \\
\hline No & $1,640(84.0)$ & 0.0003 & $382(19.5)$ & $<.0001$ \\
\hline \multicolumn{5}{|l|}{ No. children/HH } \\
\hline 1 & $841(85.5)$ & & $242(24.6)$ & \\
\hline 2 & 1,084 (83.9) & & $260(20.1)$ & \\
\hline 3 & $141(81.6)$ & & $31(18.0)$ & \\
\hline$>3$ & $10(86.7)$ & 0.3952 & 0 & \\
\hline \multicolumn{5}{|l|}{ Economic/wealth quintile } \\
\hline First $<-0.4761$ (poorest) & $414(82.6)$ & & $95(19.0)$ & \\
\hline Second $[-0.4761,-0.2974]$ & $430(84.2)$ & & $122(23.8)$ & \\
\hline Third $[-0.2974,-0.1337]$ & $419(84.8)$ & & $124(25.2)$ & \\
\hline Fourth $[-0.1337,0.0621]$ & $431(88.6)$ & & $97(19.9)$ & \\
\hline Fifth $\geq 0.0621$ (wealthiest) & $381(81.8)$ & 0.0673 & $95(20.3)$ & 0.0843 \\
\hline \multicolumn{5}{|l|}{ Education of caretaker } \\
\hline No education & $1,560(84.9)$ & & $409(22.3)$ & \\
\hline Primary education only & $404(83.4)$ & & $97(20.0)$ & \\
\hline Higher education & $112(80.6)$ & 0.4691 & $27(19.3)$ & 0.4755 \\
\hline \multicolumn{5}{|l|}{ History of severe malaria } \\
\hline Yes & $496(89.3)$ & & $143(25.8)$ & \\
\hline No & $1,580(83.0)$ & 0.0029 & $390(20.5)$ & 0.0224 \\
\hline \multicolumn{5}{|l|}{ Recent treatment with CQ } \\
\hline Yes & $801(86.2)$ & & $223(24.0)$ & \\
\hline No & $1,275(83.3)$ & 0.0829 & $310(20.2)$ & 0.0523 \\
\hline \multicolumn{5}{|c|}{ Slept under a net the previous night $\ddagger$} \\
\hline Yes & $127(81.2)$ & & $24(15.5)$ & \\
\hline No & $1,928(84.7)$ & 0.2866 & $510(22.0)$ & 0.0524 \\
\hline
\end{tabular}

with an increased risk of moderate-to-severe anemia compared with children with a density of infection $\leq 500 / \mathrm{mm}^{3}$ (density of infection $501-5,000 / \mathrm{mm}^{3}, \mathrm{OR}=1.3,95 \% \mathrm{CI}=$ $0.9-1.9$; density of infection $5,001-20,000 / \mathrm{mm}^{3}$, OR $=1.5$, $95 \%$ CI $=1.0-2.3$; density of infection $>20,000 / \mathrm{mm}^{3}$, OR $=$ $2.3,95 \% \mathrm{CI}=1.4-3.8, P<0.009)$.

\section{DISCUSSION}

We determined the prevalence of anemia, parasitemia, and clinical malaria in 2,532 children $<5$ years of age during the high malaria transmission season in three rural districts in Togo. The selected districts are representative of the variation of malaria transmission within Togo and describe a population and country from which there is a scarcity of data on malaria epidemiology.

This burden of malaria proved substantial; $62.2 \%$ of children were parasitemic: almost a quarter of these children had clinical malaria and almost a quarter $(24.0 \%)$ were moderate to severely anemic. This was consistent with the perceived high burden of malaria-related illness as reported by the caretakers. In the 2 weeks before the survey, $>20 \%$ had sought health care for their child because of a febrile illness, and more than one third of children had been treated with antimalarials. Wide-scale treatment with partially effective malaria drugs may not clear most infections but will lower parasite densities. Based on rapid malaria test results, the prevalence of malaria infection was somewhat higher than those based on slides $(72.3 \%)$. This difference could be explained by recent treatment of clinical illness resulting in clearance of a (small) subset of malaria infections in the last week. As such, the observed clinical malaria prevalence may be an underestimation of the true burden of clinical illness caused by malaria. The majority of clinical malaria cases also occurred below the age of 2 years, whereas parasite prevalence increased until 2-3 years of age before leveling off and remaining high.

Overall, one in five children were moderately to severely anemic at the time of the survey. The main burden of anemia also occurred in the first 2 years of life, with the peak pro- 


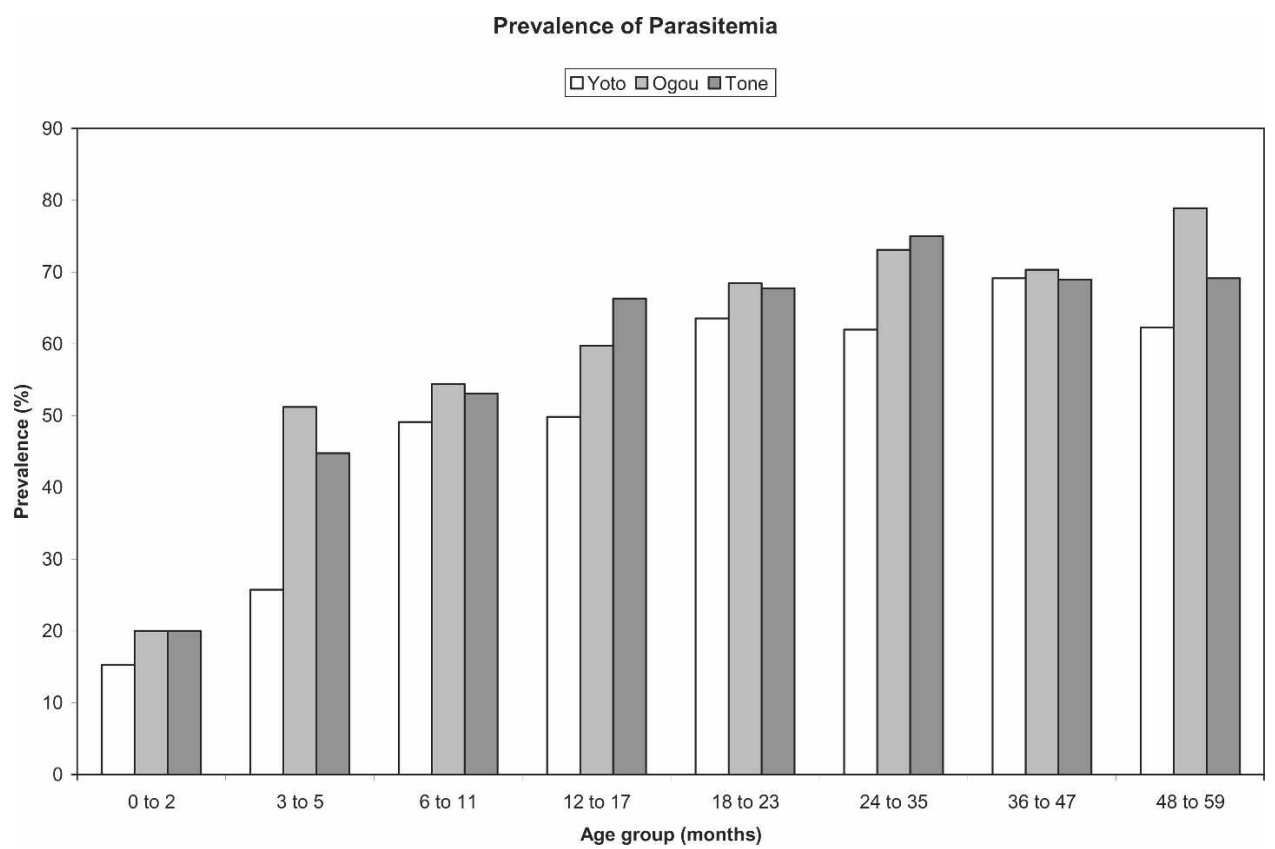

FIGURE 3. Prevalence of microscopically confirmed parasitemia by age group.

portion of moderate-to-severe anemia in children between the ages of 6 and 17 months, indicative of a population that is exposed to high malaria transmission levels. The age-related burden of malaria is consistent with previous studies characterizing malaria morbidity patterns in West Africa. ${ }^{8,9}$ Modiano and others, ${ }^{9}$ in a health facility-based study in Burkina Faso in an area of documented intense transmission, found that $78.2 \%$ of cases of severe malaria in rural areas occurred in children $<2$ years of age. Similarly, Binka and others ${ }^{8}$ found parasite densities and rates of febrile illness highest in children between 6 and 11 months of age and Hb levels lowest in this same age range. Health facility-based surveillance data being collected by the $\mathrm{MOH}$ with support from the Centers for Disease Control as part of the multi-disciplinary evaluation of the impact of the campaign confirm the main burden of malaria occurring in the first 2 years of life $(\mathrm{MOH}$ Togo; National Immunization Program, Centers for Disease Control, unpublished data).

If the observed burden of malaria and anemia in these three districts is extrapolated to regional and national levels, we estimate that $>197,000$ Togolese children $<5$ years of age were moderately to severely anemic at the time of the survey.

\section{Prevalence of Clinical Malaria}

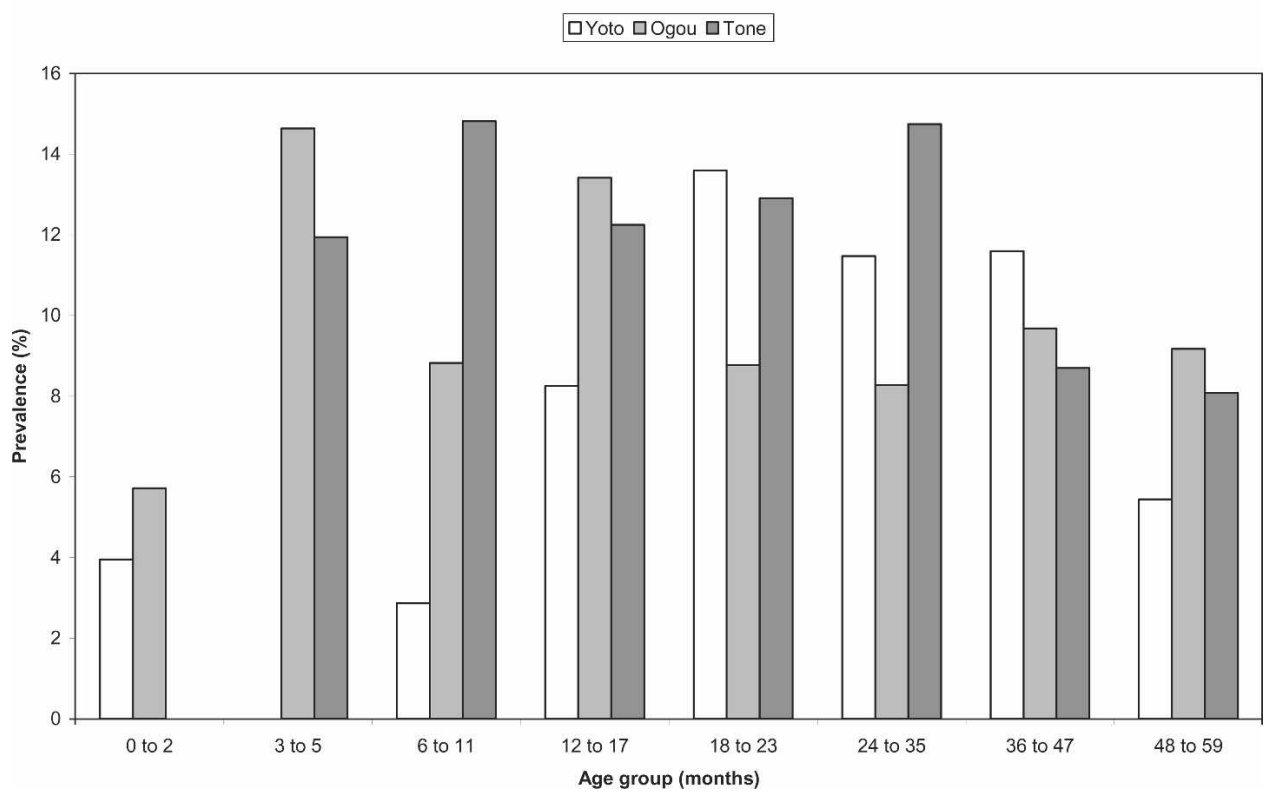

FIGURE 4. Prevalence of clinical malaria (parasitemia and documented fever) by age group. 
Likewise, $>116,000$ Togolese children $<5$ years of age would have clinical malaria at the time of the survey. The 2004 Cochrane Collaboration Review of ITNs found a $50 \%$ reduction in episodes of uncomplicated malaria in areas of stable transmission and an average increase of $1.7 \%$ packed cell volume in $\mathrm{Hb}$ level in children $<5$ years of age. ${ }^{10}$ Based on these effect estimates, ITNs (at 100\% coverage) would have the potential to reduce the number of cases of moderate to severe anemia and clinical malaria by $\sim 63,000$ and 58,000 children $<5$ years of age in Togo, respectively. At the time of this survey, however, $<10 \%$ of the children were sleeping under a net, most of the nets in use were untreated, and ownership was strongly linked to household socio-economic status, with the lowest level of ownership in the poorest part of the population.

Three months later, Togo hosted the first integrated national distribution of $>900,000$ free, LLITNs linked to a measles immunization campaign. This morbidity survey is part of extensive multi-disciplinary monitoring and evaluation efforts surrounding this campaign and provides the baseline of the morbidity impact component. While monitoring and evaluation of impact forms a core part of present efforts to rapidly scale up malaria control efforts, the optimal methodology for national level impact evaluations is still being developed because contemporaneous unprotected control groups are not available after implementation of national control efforts. Population-based data have been the gold standard for showing impact of interventions on the health of the community. Health facility-based data alone, although more practical logistically, may have limited usefulness in estimating changes in health status in rural Africa because only a small percentage of individuals with malaria will report to a health facility. ${ }^{11,12}$ The international Monitoring and Evaluation Reference Group (MERG) recommends the use of repeated large-scale cross-sectional studies at peak malaria transmission to assess control impact, and suggested the assessment of moderate to severe anemia as a core indicator of malaria transmission and control progress. ${ }^{13}$ With the large sample sizes per district in this survey and the enrollment of $>95 \%$ of randomly selected eligible households, these data provide precise and representative estimates of the prevalence of malaria and anemia at peak malaria transmission in children $<5$ years of age, most of whom were targeted during the December 2004 National Integrated Child Health Campaign.

Anemia is multi-causal and may be a consequence of malaria, nutritional deficiencies, hemoglobinopathies, and other infections. Among pre-school children in sub-Saharan Africa, however, it is predominantly caused by iron deficiency and malaria. ${ }^{14,15}$ A correlation of malaria and anemia has been reported in several health facility-based and smaller community-based studies in West Africa. ${ }^{9,16,17}$ Helminth infection also contribute to anemia, and several studies in Togo and the surrounding countries have documented high prevalence rates in young children. ${ }^{18,19}$ While helminth infections and other causes will have contributed to the substantial prevalence of anemia in this study, the strong observed relationship between parasitemia and moderate anemia, and the similarities of age categories at risk for both moderate anemia and parasitemia, would suggest that moderate anemia in children $<5$ years is a suitable marker of malaria transmission in Togo.

The use of portable $\mathrm{Hb}$ photometers (Hemocue) to allow direct diagnosis of $\mathrm{Hb}$ level and treatment of anemia at the time of the survey also worked well in this survey and confirmed their reliability, robustness, and user-friendliness under field conditions. Of the 2,532 children enrolled in the survey, $\mathrm{Hb}$ assessments were successfully performed in 2,524 $(99.7 \%)$. None of the six machines in use required any servicing or recalibration during the survey. The reliability of these also supports the recent MERG recommendations of moderate to severe anemia as a useful indicator in national large-scale field-based surveys to assess the burden of malaria and the impact of malaria control interventions. ${ }^{20,21}$

Nevertheless, repeated national level community-based cross-sectional evaluations are logistically challenging, requiring considerable resources and funds, and often do not represent the burden of disease throughout the year. While recommendations suggest to measure at peak transmission, many countries, including Togo, host a range of climatic and malaria transmission settings. In Togo, the climate ranges from tropical and humid in the south to semi-arid savannah type in the most northern part and the peak transmission may occur at different time-points of the year in different regions. Implied differences in malaria transmission patterns are based on differences in rainfall patterns, but whether these result in a variation in the burden of malaria among the three regions is unknown. The reported burden of malaria based on moderate-to-severe anemia was higher in the northern two districts across most age ranges. Interestingly, however, the prevalence of clinical malaria did not differ significantly between districts. The observed geographic variations in anemia could be because of the time period during which the survey was conducted. The northern two districts were in the middle of one continuous rainy season. In contrast, in Yoto, the southern district, the survey coincided with a period of infrequent rain showers, just before the second peak of the bimodal rainfall season. Differences could also be part of the natural range of variation in transmission over time, to some extent linked to regional and annual variations in rainfall. Because monthly rainfall figures in 2004 proved to be reasonably average compared with those from the past 30 years (data not shown), these data likely represent the burden (in the month of September) during an average transmission season.

The baseline results also provided information that is useful to the implementation of integrated campaigns, such as the campaign that followed in December 2004, which targeted children between the ages of 9 months and 5 years after measles vaccination targets. These data indicate that such a campaign could miss some of the most vulnerable children $<9$ months of age, and their immediate and more long-term success may depend on the sharing of bed spaces, and thus LLITNs with the youngest infants and newborn children within the house. Future integrated campaigns in areas with a similar burden of malaria should try to include all children $<5$ years of age for ITN distribution. As part of the multidisciplinary evaluation, a detailed post-intervention coverage evaluation was undertaken as well, which will be described in a separate paper.

In conclusion, this study provides good quality baseline data on the burden of malaria in young children before the first national integrated ITN and measles vaccination campaign in Togo. In addition, these data provide the basis for assessment of the suitability of MERG-recommended indica- 
tors in a country with a variety of malaria transmission patterns.

Received January 18, 2006. Accepted for publication June 11, 2006.

Acknowledgments: We are grateful to the parents and guardians of the children who participated in the survey and the many people that assisted with this project. We thank Dr. Potougnima Tchamdja from the MoH Togo, Norbert Paniah, Antoinette Awaga, Blaise Edoh, and Messan Nyonato from the Togolese Red Cross, Bart Peeters and Chris Weeks from DHL, and Phillip Brun from Sanofi-Synthelabo for logistical support. At the International Federation of the Red Cross and Red Crescent Society, the authors thank Nick Farrell, Jean Roy, and Bernard Moriniere for assistance, and at the Canadian Red Cross, Marcy Erskine and Mel Peters. We are grateful to Anatoly Frolov for programming the PDA-GPS-related software. From WHO, the authors thank Bernard Nahlen and John Miller for critically reviewing the questionnaire.

Financial support: This survey was funded by Canadian Red Cross. Arsucam, the anti-malarial drug used in the survey, was kindly donated by Sanofi-Synthelabo in France. DHL donated their assistance with the transportations of study shipment. Dr. Terlouw acknowledges financial support from the Canadian Red Cross.

Disclaimer: The opinions or assertions contained in this manuscript are the private ones of the authors and are not to be construed as official or reflecting the view of the US Public Health Service or Department of Health and Human Services. Use of trade names is for identification only and does not imply endorsement by the US Public Health Service or Department of Health and Human Services.

Authors' addresses: M. James Eliades, Adam Wolkon, Sara B. Crawford, William A. Hawley, and Allen W. Hightower, Centers for Disease Control and Prevention, 4770 Buford Highway, MS F-22, Atlanta, GA 30341. Kodjo Morgah, Ameyo Dorkenoo, and Yao Sodahlon, Programme National de Lutte contre le Paludisme (PNLP), BP518, Lome, Togo. Feiko O. Ter Kuile and Dianne J. Terlouw, Child \& Reproductive Health Group, Liverpool School of Tropical Medicine, Pembroke Place, L3 5QA Liverpool, UK.

\section{REFERENCES}

1. Ministry of Health P, Togo, 2003. Rapport: Collecte Dynamique des Données de Morbidité et de Mortalité sur le Paludisme Pour le Suivi et l'Evaluation de FRP au Togo. Lome, Togo: Ministry of Health.

2. 2001. The Mapping Malaria Risk in Africa (MARA). Available at http://www.mara.org.za.

3. Takpa VMK, Gbendonou P, Gittelman D, Eliades MJ, Cairns L, 2005. Distribution of insecticide-treated bednets during and integrated nationwide immunization campaign-Togo, West Africa, December 2004. MMWR Morb Mortal Wkly Rep 54 994-996.
4. World Health Organization, 2002. The World Health Report, Statistical Annex. Geneva: World Health Organization.

5. Ministry of Health T, 2003. Principaux Indicateurs de Sante 2002. Lome, Togo: Ministry of Health.

6. UNICEF, 2000. MICS2 Survey. New York, NY: UNICEF.

7. World Bank, 2000. African Development Indicators 2000. Washington, DC: World Bank.

8. Binka FN, Morris SS, Ross DA, Arthur P, Aryeetey ME, 1994. Patterns of malaria morbidity and mortality in children in northern Ghana. Trans R Soc Trop Med Hyg 88: 381-385.

9. Modiano D, Sirima BS, Sawadogo A, Sanou I, Pare J, Konate A, Pagnoni F, 1998. Severe malaria in Burkina Faso: Influence of age and transmission level on clinical presentation. Am J Trop Med Hyg 59: 539-542.

10. Lengeler C, 2000. Insecticide-treated bed nets and curtains for preventing malaria. Cochrane Database Syst Rev: CD000363.

11. Bremen J, 2001. The ears of the hippopotamus: Manifestations, determinants, and estimates of the malaria burden. Am J Trop Med Hyg 64: 1-11.

12. Deming MS, Gayibor A, Murphy K, Jones TS, Karsa T, 1989. Home treatment of febrile children with antimalarial drugs in Togo. Bull World Health Organ 67: 695-700.

13. World Health Organizaiton, 2003. Minutes MERG Anaemia Task Force Meeting. Geneva: World Health Organization.

14. Menendez C, Fleming AF, Alonso PL, 2000. Malaria-related anaemia. Parasitol Today 16: 469-476.

15. Stoltzfus R, 2001. Defining iron-deficiency anemia in public health terms: A time for reflection. $J$ Nutr 131: 565S-567S.

16. Koram KA, Owusu-Agyei S, Utz G, Binka FN, Baird JK, Hoffman SL, Nkrumah FK, 2000. Severe anemia in young children after high and low malaria transmission seasons in the Kassena-Nankana district of northern Ghana. Am J Trop Med Hyg 62: 670-674.

17. Owusu-Agyei S, Fryauff DJ, Chandramohan D, Koram KA, Binka FN, Nkrumah FK, Utz GC, Hoffman SL, 2002. Characteristics of severe anemia and its association with malaria in young children of the Kassena-Nankana District of northern Ghana. Am J Trop Med Hyg 67: 371-377.

18. Pit DS, Rijcken FEM, Raspoort EC, Baeta SM, Poldereman AM, 1999. Geographic distribution and epidemiology of Oesophogostomum bifurcum and hookworm infections in humans in Togo. Am J Trop Med Hyg 61: 951-955.

19. Storey PA, Steenhard NR, Van Lieshout L, Anemana S, Magnussen P, Polderman AM, 2001. Natural progression of Oesophagostomum bifurcum pathology and infection in a rura community of northern Ghana. Trans R Soc Trop Med Hyg 95 295-299.

20. World Health Organization, 2003. Minutes MERG Anemia Task Force Meeting. Geneva: World Health Organization.

21. Korenromp EL, Armstrong-Schellenberg JR, Williams BG, Nahlen BL, Snow RW, 2004. Impact of malaria control on childhood anaemia in Africa-a quantitative review. Trop Med Int Health 9: 1050-1065. 